\title{
Morphological and Thermal Properties of Starches Isolated from White and Pigmented Sorghum Landraces Grown in Hyper Arid Regions
}

\author{
Nadia Boudries ${ }^{1}$, Boubekeur Nadjemi ${ }^{2}$, Naima Belhaneche-Bensemra ${ }^{3}$ and Marianne Sindic ${ }^{1}$ \\ 1. Laboratory of Quality and Safety of Food Products, Gembloux Agro-Bio Tech, University of Liege, Passage des Déportés 2, \\ B-5030 Gembloux, Belgium \\ 2. Department of Chemistry, Laboratory of Bioactive Products and Biomass Valorization Research, High School of Teachers \\ Training, BP 92 Kouba, Algiers 16050, Algeria \\ 3. Department of Environmental Engineering, Polytechnic School of Algiers, 10 Avenue Hassan Badi, El-Harrach, Algiers 16131, \\ Algeria
}

Received: May 6, 2014 / Published: August 20, 2014.

\begin{abstract}
The starches were isolated by alkaline extraction from white and red sorghum, predominant cultivars in the Sahara of Algeria. Morphological, thermal properties and amylose content of isolated starches were examined. The starches of two sorghum landraces of white and pigmented kernels growing in hyper arid environmental conditions showed significant differences in granule size, amylose content and thermal behavior which ultimately affect the physicochemical and functional properties. When observed using environmental scanning electron microscopy (ESEM). The starch granules showed polyhedral shape. Some of them showed pinholes. The granular size ranged between 6.325-39.905 $\mu \mathrm{m}$ and 7.096-44.774 $\mu \mathrm{m}$, respectively for white and red sorghum starches. The granule size distribution was unimodal. The amylose content in white sorghum starch (27.1\%) was higher than that in red sorghum (24.8\%). Differential scanning calorimetry (DSC) analysis revealed that sorghum starches present higher temperatures at the peak $\left(70.60{ }^{\circ} \mathrm{C}\right.$ and $72.28{ }^{\circ} \mathrm{C}$ for white and red sorghum starches, respectively) and lower gelatinization enthalpies ( $9.087 \mathrm{~J} / \mathrm{g}$ and $8.270 \mathrm{~J} / \mathrm{g}$ for white and red sorghum starches, respectively) than other cereal starches. The determination of these properties is relevant to the comprehension of starch and starch-based foods digestibility in order to direct them towards the specific applications in food and nonfood sectors.
\end{abstract}

Key words: Sorghum starch, granule morphology, size distribution, amylose, thermal properties.

\section{Introduction}

Sorghum (Sorghum bicolor (L.) Moench) is one of the cereal grains of gramineae family. It is the fifth more significant cereal in the world and it is the leading cereal grain in Africa [1]. The plant is drought resistant and grows using low-input agricultural fertilizers.

The sorghum kernels differ widely in size, weight

Corresponding author: Nadia Boudries, Ph.D., research fields: biotechnology and food chemistry. E-mail: nboudires@yahoo.fr. and color.

Tidikelt (Algeria) includes a significant number of sorghum genotypes. It is a hyper arid region of Algerian Sahara bordering the sahel countries as Niger, and Mali, an important sorghum producers countries. The few studies on Algerian sorghum were carried out by Gast and Adrian [2] and Ozenda [3] and treated only the botanical aspects of the landraces. The basic races of durra, caudatum and bicolor were identified using the sorghum descriptor. The common name given for white sorghum is tafsout el baïda or talak. 
For red sorghum the terms tafsout el hamra and abora are used. Sorghum was cultivated using traditional methods in high maturity temperature conditions and they were irrigated with saline underground water.

Starch is the most abundant carbohydrate in cereal grains, being found in the endosperm and has a major role as energy source, providing $70 \%-80 \%$ of the calories consumed by human worldwide [4]. It is present in normal sorghum kernel about $60 \%-80 \%$ according to Abd Elmoneim et al. [5]. FAO [6] in its capstone work gave ranging between $55.6 \%$ and 75.2\%. Sena-Salivar \& Rooney [7] and Bemiller \& Whistler [8] found values of starch content between $72.3 \%$ and $75.1 \%, 60 \%$ and $77 \%$, respectively.

Morphology of starch granules such as shape and size are characteristics of their botanical origin [9], and exhibit significant differences [10]. Starch composition, amylopectin structure and gelatinization properties are greatly affected by environmental temperature [11].

Granule size and amylose/amylopectin ratio and gelatinization temperature have effect on the physicochemical properties of starch and these physicochemical properties influence the quality of starch and starch based products. Furthermore, they are essential to determine starch potential uses.

Many studies were carried out on the properties of corn and potato starches and the genotypic and environmental effect on starch characteristics [12], but little interest was related to the sorghum starches [13], and even less to the starch of sorghum growing in the hyper arid ecosystems of Algeria.

This article focuses on morphological and thermal properties and amylose content of isolated starches from Algerian white and red sorghum grains. Further researches on the starch properties reveal the genotype and environmental effect and allow the understanding of starches behavior during their potential applications and control their transformations in food and nonfood sectors.

\section{Materials and Methods}

\subsection{Materials}

Sorghum landraces were grown in Tidikelt, a hyper arid region situated in the Sahara of Algeria and known to have temperatures ranging from $7.8{ }^{\circ} \mathrm{C}$ to $45.2{ }^{\circ} \mathrm{C}$ and very low annual rainfall rate $(16.9 \mathrm{~mm})$ (Data of Algerian Meteorology Office). The mean value of sizes (length, width, thickness, density and weight of 1000 kernels) which characterize kernels of the white and red sorghum cultivars were given in Table 1.

The dimensions seem to be close between the white and pigmented sorghum kernels, and except the density which was lower, the kernel size values correspond to those given for commercial US sorghum [7]. So these sorghum landraces can be marketed and competitive.

Almost chemical products used in different experiments were Sigma Chemical Co. and Merck.

\subsection{Methods}

\subsubsection{Starch Isolation and Purification}

Starch was isolated from two sorghum cultivars by alkali extraction of protein as proposed by Beta et al. [14], Beta \& Corke [15] and Pérez Sira \& Amaiz [16].

For white sorghum, $500 \mathrm{~g}$ of grains were steeped for a night in $0.25 \% \mathrm{NaOH}$ solution. They were washed and then they were crushed using a warring blender (Eberbach, Michigan, USA) at full speed during

Table 1 Mean values of kernels size of white and red sorghum cultivars.

\begin{tabular}{llllll}
\hline Sample & Length $(\mathrm{mm})$ & Width $(\mathrm{mm})$ & Thickness $(\mathrm{mm})$ & Density $(\mathrm{g} / \mathrm{L})$ & Weight of $1000 \mathrm{kernels}(\mathrm{g})$ \\
\hline White sorghum & 4.52 & 3.85 & 2.53 & 692.850 & 33.05 \\
Red sorghum & 4.49 & 3.53 & 2.41 & 736.550 & 27.70 \\
US sorghum & 4 & 2 & 2.5 & $1,280-1,360$ & $25-35$ \\
\hline
\end{tabular}


$10 \mathrm{~min}$. The suspensions were passed through a set of sieves $(50 \mu \mathrm{m}$ to $355 \mu \mathrm{m})$. The filtrates were centrifuged (5,000 rpm during $20 \mathrm{~min})$. The layer of residual proteins, fibers and lipids is scraped each time. The operation was repeated four times until disappearance of sludge layer. The starch was centrifuged in pure ethanol and finally in distilled water. The extract was then dried at $40{ }^{\circ} \mathrm{C}$ overnight.

For red sorghum, the grains were soaked in $467 \mathrm{~mL}$ of $5.25 \% \mathrm{NaOCl}$ solution and $50 \mathrm{~g}$ of $\mathrm{KOH}$ and heated at $60{ }^{\circ} \mathrm{C}$ during $7 \mathrm{~min}$ under agitation. The mixture was cooled at room temperature. The grains are washed until the red color disappears, after that the starch was isolated as described earlier [16].

\subsubsection{Starch Content}

The starch content was determined using a polarimetric method of Ewers, ISO 10520 (1997). This method includes the determination of the optical activity of soluble sugars obtained after treatment of the sample by the diluted hydrochloric acid at high temperature, defection and filtration.

\subsubsection{Starch Color}

The color of the extracted starches was given using a spectrocolorimeter Miniscan of Hunterlab (Virginia, USA). White and black plates are used beforehand to calibrate the apparatus. This measurement is quantified by Hunterlab system (1958).

\subsubsection{Scanning Electron Microscopy}

Granule shape and surface of native starches were examined and photographed using a FEI Philips ElecroScan environmental scanning electron microscopy (ESEM) model XL 30-FEG equipped with a field emission electron gun. A small amount of granule starch samples were mounted on circular aluminum stubs with double sticky tape. The image processing is made using microscope software control. An acceleration potential of $5.00 \mathrm{kV}$ was used.

\subsubsection{Granule Size Distribution}

The granule size distribution of isolated starches was determined with a laser diffraction particle size analyzer (Malvern Mastersizer 2000, Malvern
Instruments Limited, Worcestershire, UK). After alignment of the laser beam and elimination of background noise, some drops of $10 \%$ starch suspension were injected in the measuring cell and subjected to ultrasounds to disperse granule clusters.

\subsubsection{Amylose Content}

Amylose content was determined by the method of Morrison and Laignelet [17]. It is based on the colorimetric determination of amylose according to the color of the polyodide complex; the principle consists in dissolving $50 \mathrm{mg}$ of the starch $(\mathrm{db})$ in $5 \mathrm{~mL}$ of urea-dimethylsulfoxyde U-DMSO (1:9 v/v). The starch suspension in screw-capped tubes was vortexed and placed in a water bath at $95{ }^{\circ} \mathrm{C}$ during $60 \mathrm{~min}$ under agitation until complete solubilization and cooled at room temperature. $100 \mu \mathrm{L}$ of the soluble starch is added to $9.7 \mathrm{~mL}$ of distilled water and 200 $\mu \mathrm{L}$ of iodine solution $\left(0.5 \mathrm{~g} \mathrm{KI}\right.$ and $0.05 \mathrm{~g} \mathrm{I}_{2}$ in $25 \mathrm{~mL}$ of distilled water). The blend was immediately mixed and placed in the darkness during $20 \mathrm{~min}$. The absorbance of the formed blue complex was then measured at $635 \mathrm{~nm}$ using a Shimadzu spectrophotometer UV-2401 (Kyoto, Japan). Amylose content was calculated from a standard curve prepared using blends of pure potato amylose and pure maize amylopectin from ICN Biomedicals Inc (Ohio, USA). Three replicate samples were used in this analysis.

\subsubsection{Differential Scanning Calorimetry}

The thermal behavior of the starch samples is evaluated using an analyzer enthalpy differential scanning calorimetry 2920 (TA Instruments, New Castle DE, USA). The apparatus was calibrated in temperature and enthalpy with eicosane $\left(T_{o}=36.8^{\circ} \mathrm{C}\right.$ and $\Delta H=247.4 \mathrm{~J} / \mathrm{g})$ and indium $\left(T_{o}=156.6^{\circ} \mathrm{C}\right.$ and $\Delta H=28.71 \mathrm{~J} / \mathrm{g})$. Calorimetric measurements were carried out on starch samples of $5 \mathrm{mg}(\mathrm{db})$ dispersed in $10 \mu \mathrm{L}$ of distilled water. The samples were hermetically sealed in aluminum capsule and allowed to stand $1 \mathrm{~h}$ at room temperature. The suspensions were then heated in DSC at a rate of $5^{\circ} \mathrm{C} / \mathrm{min}$ from $10{ }^{\circ} \mathrm{C}$ to $120{ }^{\circ} \mathrm{C}$. An empty aluminum pan was used as 
reference. Temperature of onset $\left(T_{o}\right)$, peak $\left(T_{p}\right)$, and conclusion $\left(T_{c}\right)$ of gelatinization and endothermic heat $\Delta H$ are given starting from the thermograms.

\section{Results and Discussion}

\subsection{Isolated Starches}

Starch content in sorghum kernels of white cultivar $(66.81 \% \pm 0.27 \%)$ was founded slightly higher than red one $(65.26 \% \pm 0.11 \%)$. The isolation starch methods for sorghum cultivars present some difficulties because of their protein matrix that strongly retains the starch granules which leads to low extraction yield (59\%-60\%). The role of sorghum endosperm protein matrix and cell wall components in limiting extract is a research focus [18]. However, the purity of starches extracted was high with the values of $93.31 \%$ and $94.10 \%$, respectively for red and white sorghum starch extracted.

\subsection{Color Starches}

The data of color parameters are shown in Table 2. The extracted starches have a great clearness; the values of color lightness $L$ are 92.91 and 91.06, respectively for white and red sorghum (Table 1). This result showed that the starches are pure; indeed Wang et al. [19] estimated that the starches with $L$ value higher than 90 were purity. Pérez Sira \& Amaiz [16], by using the same process of steeping, obtained a higher value for the starch isolated from white sorghum (91.3) but lower for the starch of pigmented sorghum (78.4). The values of color yellowness $b$ are 3.58 and 4.15 , respectively for white sorghum and red sorghum starches; they express a tendency of color towards yellow. These values are lower than those found by Pérez Sira \& Amaiz [16] which was 10.1 for white sorghum starch and 16.5 for the pigmented sorghum starch. The results confirmed that our varieties have less yellow pigment and that the residual rate of proteins and lipids was weaker. The starch of pigmented sorghum extracts has a negative value of color redness $a$ after steeping in the presence of sodium hypochlorite, showing that the red color disappeared as a result of bleach effect.

\subsection{Morphological Properties}

The granule starches of the two cultivars examined using the ESEM showed heterogeneity of shape and size. The granules were observed to be polygonal in shape and some of them had oval shape. These observations were similar to those done by other authors as Radley [20] and Hoseney [21]. This heterogeneity could be caused by the difference in developing location. The starch granules in the floury endosperm are more rounded, whereas those in the horny endosperm are more angular. Many researchers have suggested that as the amylose content increases, the irregularity of starch granule shape also increases [19].

No significant variations in size and shape for the white and red sorghum granules were observed when viewed by ESEM (Figs. 1 and 2). Insignificant number of broken or damaged granules was observed. At high magnification, some granules showed pin holes locally at the smooth surface (Figs. 3 and 4). The same observation was reported by Huber \& BeMiller [8], Benmoussa et al. [22] and Singh et al. [23]. The pin holes appeared due to the action of amylases during the growth of sorghum grain or the starch isolation process [24].

\subsection{Granule Size Distribution}

The size of granule starch plays a significant role in food product quality and the properties of biodegradable plastic films [25]. It is a characteristic of their botanical origin and can be affected by environmental temperature. Indeed, Matsuki et al. [11] found that size granule reduced at high temperature in barley.

Table 2 Color parameters of white and red sorghum starches.

\begin{tabular}{lll}
\hline $\begin{array}{l}\text { Color } \\
\text { parameters }\end{array}$ & White sorghum starch & Red sorghum starch \\
\hline L & 92.91 & 91.06 \\
A & -0.26 & -0.48 \\
B & 3.58 & 4.15 \\
\hline
\end{tabular}



Pigmented Sorghum Landraces Grown in Hyper Arid Regions

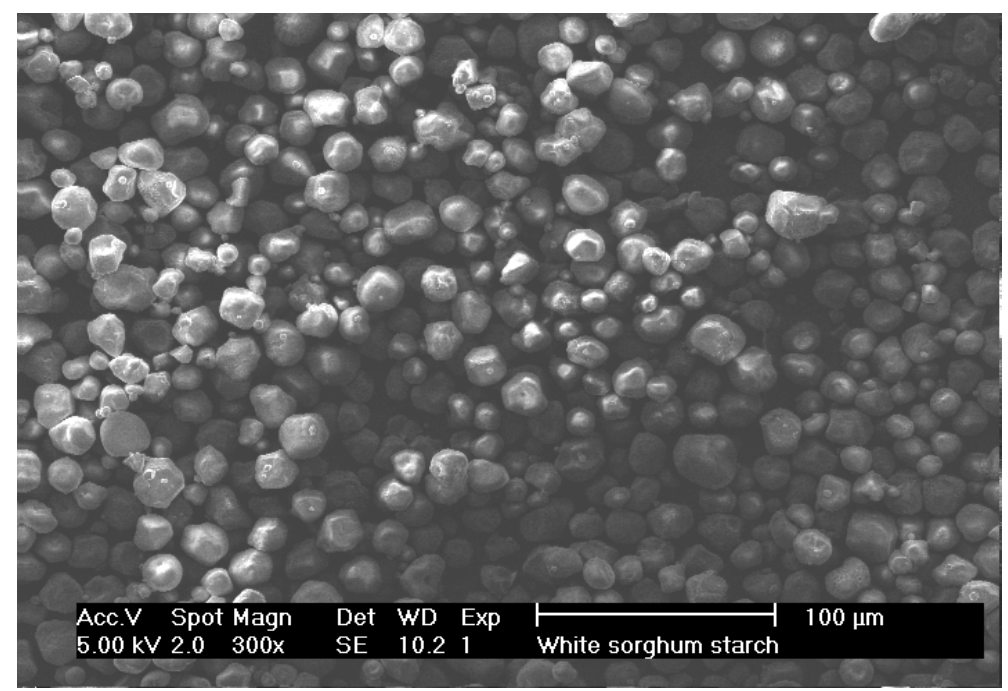

Fig. 1 Scanning electronic micrograph of white sorghum starch granules, 300x.

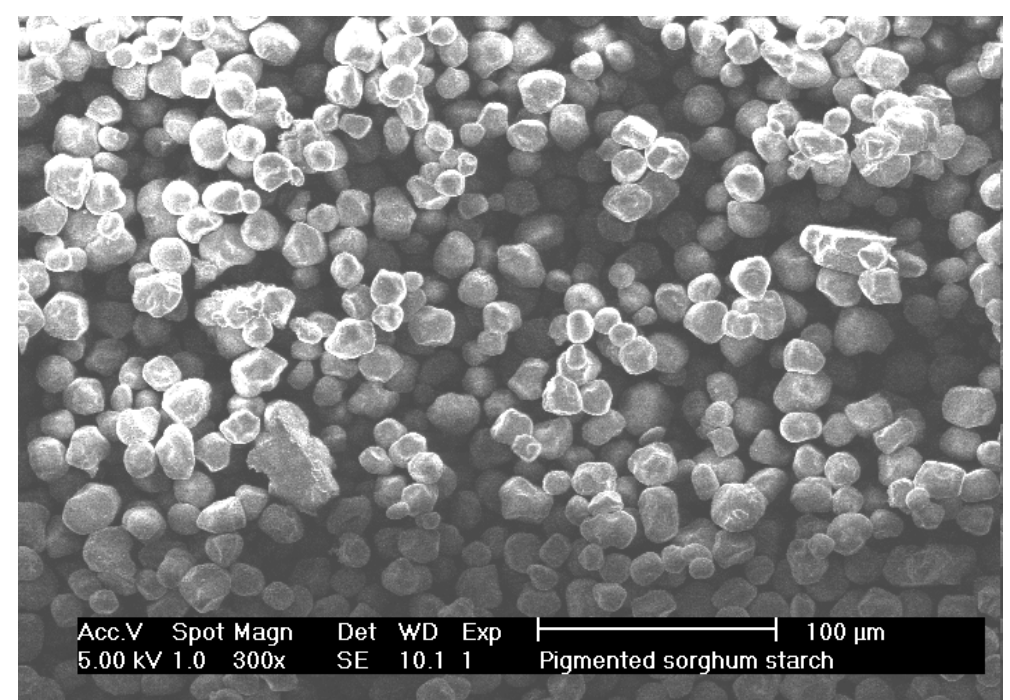

Fig. 2 Scanning electronic micrograph of red sorghum starch granules, 300x.

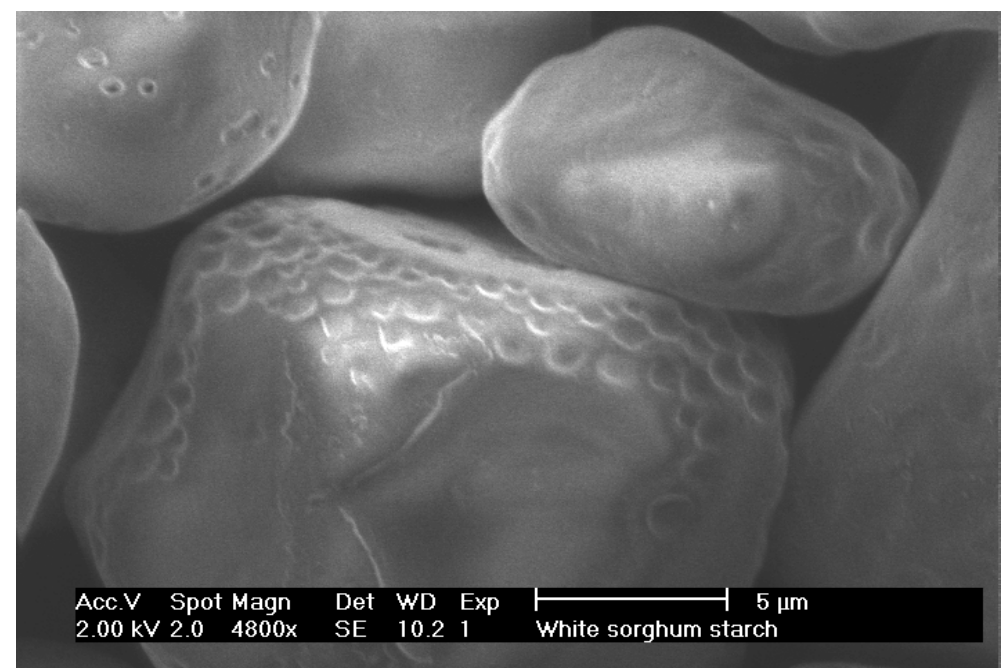

Fig. 3 Scanning electronic micrograph of white sorghum starch granules. 
Morphological and Thermal Properties of Starches Isolated from White and Pigmented Sorghum Landraces Grown in Hyper Arid Regions

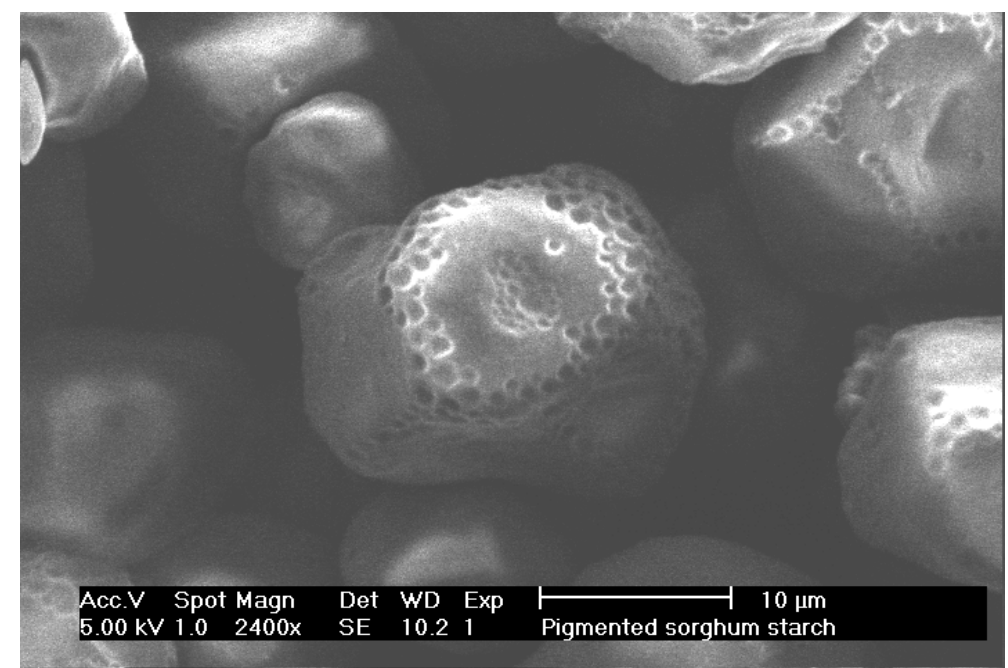

Fig. 4 Scanning electronic micrograph of red sorghum starch granules, 2400x.

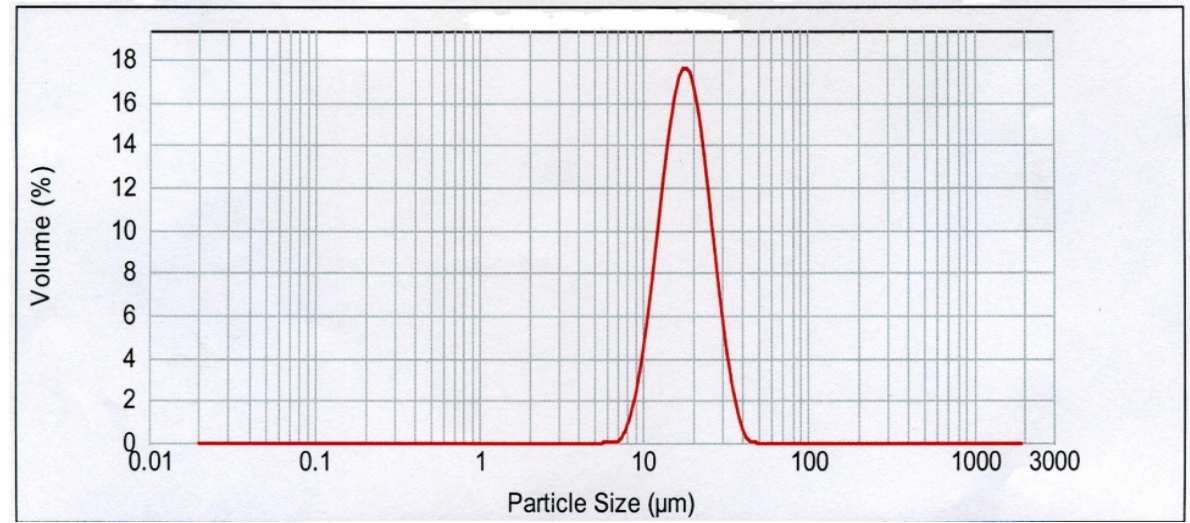

Fig. 5 Granule size distribution of white sorghum starch.

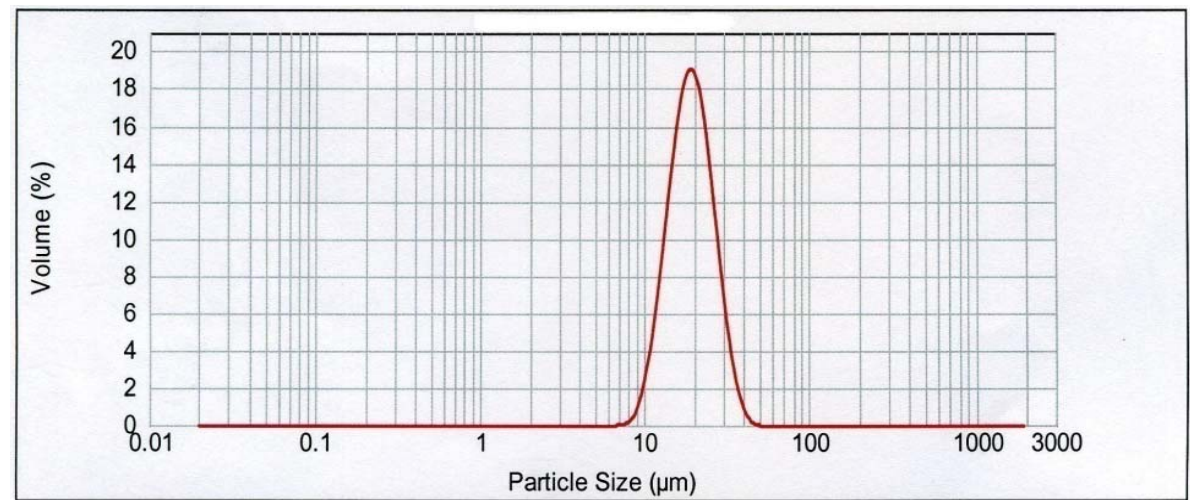

Fig. 6 Granule size distribution of red sorghum starch.

It has showed that physicochemical properties have been correlated with the average granule size of starches separated from different plant sources $[9,10$, 26]. The starches isolated from the two sorghum cultivars exhibit a unimodal distribution as shown in Figs. 5 and 6 . The granule size of white sorghum starch varies between $6.33 \mu \mathrm{m}$ and $39.91 \mu \mathrm{m}$ and that of the pigmented sorghum varies from $7.10 \mu \mathrm{m}$ to $44.78 \mu \mathrm{m}$. Jobling [27] had estimated that granule size range of corn, wheat, potato and cassava was respectively 2-30, 1-45, 5-100 and 4-34 $\mu \mathrm{m}$.

The granule size of sorghum is nearly similar to 
those of corn and cassava, so industrially sorghum starches can replace the starch of corn and cassava in the processes, if there are no influences related to the other functional characteristics.

According to obtained results (Table 2), $90 \%$ of starch granules had $28 \mu \mathrm{m}$ size for the two sorghum cultivars. The characteristics of sorghum landraces starches found are not very exceptional from those studied on sorghum cultivated in other countries in Africa, India and America, although the significant effect of hyper arid environmental on starch properties was observed especially by reducing starch granule size. The low size of the granules and their modal distribution is a very interesting property; it allows its orientation towards particular applications (sectors of the cosmetics, pharmaceutical and textile) [27] and other innovative applications.

The analysis of the variance (ANOVA) carried out for the size of the starch granules and the values characteristic of granule size $d_{0.1}, d_{0.5}$ and $d_{0.9}$, showed that the difference was significant $(P<0.05)$. It can be deduced that the phenotypic origin and growing conditions of sorghum, have an influence on size granule starch $(10 \%, 50 \%$ and $90 \%$ granules have respectively diameters inferior to $d_{0.1}, d_{0.5}$ and $d_{0.9}$ values).

\subsection{Amylose Content}

The amylose content of starches isolated from the two sorghum cultivars showed a significant difference. The highest amylose content of $27.1 \%$ was observed for white sorghum starch. Red sorghum starches contained $24.8 \%$. The sorghum starches analyzed are considered as normal types since the rate was ranging from $21 \%$ to $34 \%$ [15]. Similar values of amylose content have been reported earlier for maize and wheat $(28 \%)[6,27]$. Sorghum genotypes grown in Zimbabwe and Indiana USA contain respectively $20.9 \%$ to $30.2 \%$ [15] and $19.2 \%$ to $22.4 \%$ of amylose [22]. The amylopectin content and ratio were $72.9 \%$,
0.4 for white sorghum and $75.2 \%, 0.3$ for pigmented sorghum. The amylose content has been reported to vary with the botanical source of the starch and is affected by the climatic and soil conditions during grain development [23]. It has an influence on granule structure and thermal properties [28].

\subsection{Gelatinization Characteristics}

The gelatinization transition temperature ( $T_{o}$ (onset), $T_{p}$ (peak) and $T_{c}$ (conclusion)) and the enthalpy of gelatinization $H$ of white and red sorghum starches were presented in Table 3.

Significant differences of gelatinization temperature and enthalpy between white and pigmented sorghum starches were obtained. The red sorghum starch showed a higher gelatinization temperature than white sorghum starch, however the enthalpy of gelatinization was weaker.

Compared to results obtained by Jenkins \& Donald [28], Jane et al. [25] and Sodhi et al. [29] for starches of other botanical sources as potato, corn, rice and wheat, local sorghum starch showed higher temperature of onset and peak and lower gelatinization enthalpy. Sorghum starch gelatinization temperature ranges of $67-73{ }^{\circ} \mathrm{C}$ have been reported for sorghum grown in South Africa and $71-81{ }^{\circ} \mathrm{C}$ for sorghum grown in India [18] and $73.2{ }^{\circ} \mathrm{C}$ for Korean waxy sorghum [30]. High temperature gelatinization

Table 3 Size of sorghum granule starches and diameters characteristic values.

\begin{tabular}{lllll}
\hline Sample & Size $(\mu \mathrm{m})$ & $d_{0.1}(\mu \mathrm{m})$ & $d_{0.5}(\mu \mathrm{m})$ & $d_{0.9}(\mu \mathrm{m})$ \\
\hline White sorghum & & 12.80 & 19.08 & 28.31 \\
starch & $6.32-39.90$ & \pm 0.06 & \pm 0.10 & \pm 0.18 \\
Red sorghum & & 11.81 & 18.21 & 27.78 \\
starch & $7.10-44.77 \pm 0.21$ & \pm 0.38 & \pm 0.53 \\
\hline
\end{tabular}

Table 4 Gelatinization characteristics of white and red sorghum starches.

\begin{tabular}{lllll}
\hline Starch source & $T_{o}\left({ }^{\circ} \mathrm{C}\right)$ & $T_{p}\left({ }^{\circ} \mathrm{C}\right)$ & $T_{c}\left({ }^{\circ} \mathrm{C}\right)$ & $H(\mathrm{~J} / \mathrm{g})$ \\
\hline \multirow{2}{*}{ White sorghum } & 66.60 & 70.60 & 76.78 & 9.087 \\
& \pm 0.18 & \pm 0.27 & \pm 0.06 & \pm 0.011 \\
\multirow{2}{*}{ Red sorghum } & 68.43 & 72.29 & 77.09 & 8.270 \\
& \pm 0.06 & \pm 0.08 & \pm 0.04 & \pm 0.032 \\
\hline
\end{tabular}

$T_{o}, T_{p}$ and $T_{c}$ indicate the temperature of the onset, peak and conclusion of gelatinization $H$ enthalpy of gelatinization. 
can be an indication of the higher stability of starch crystallites in starch molecules [31]. Starch gelatinization temperature is influenced by many factors; in particular the lengths of the various chains in the amylopectin molecule with gelatinization temperature increasing with longer chain length [18]. Moorthy [31] reported that gelatinization enthalpy depends on number of factors such as cristallinity intermolecular bonding, and it also depends on genetic and environmental factors, so it can be deduced that hyper arid environment has affected gelatinization properties of sorghum starch by increasing peak temperature. Similar observation was done previously for wheat and other species but gelatinization enthalpy was found increasing [11].

The starches cultivars of sorghum landraces studied exhibit very interesting functional properties suitable to be used in food products, but more research is required to understand the relationship between environment and characteristics and end-product quality and to extend the investigations on starch functional properties for other sorghum cultivars over the South Regions of Algeria.

\section{Conclusions}

The starches of white and pigmented sorghum cultivars grown in hyper arid environment showed significant differences in granule size, amylose content and thermal behavior which ultimately affect the physicochemical and functional properties. White and red sorghum starches showed a high gelatinization temperature and low enthalpy of gelatinization. The variations on properties between the two cultivar starches show the effects of genotype on starch functional properties and end-product quality as reported by many researchers. The effect is reported earlier for other botanical source starches. The local sorghum starches characteristics found are not very exceptional from those studied on sorghum cultivated in other countries in Africa, India and America, although the significant effect of hyper arid environmental on sorghum starch properties was observed especially by reducing starch granule size and increasing gelatinization temperature. The sorghum landraces exhibit very interesting functional properties suitable to be used in food products but more research is required to understand the relationship between characteristics, industrial applications and end-product quality and to extend the investigations on starch functional properties for other sorghum cultivars over the south regions of Algeria.

\section{Acknowledgments}

The authors thank Nassim Souami and Messaoud Bali Ouamer from Nuclear Energy Center of Algiers, Algeria and Carine Massaux from ATISA, Gembloux Agro-Bio Tech, respectively for environmental scanning electron microscopy (SEM) and Differential Scanning Calorimetry (DSC) analysis assistance.

The Belgium technical cooperation is gratefully acknowledged for its financial support.

\section{References}

[1] FAO. 1997. "World Economy of the Sorghum and the Millet: Facts, Tendencies and Prospects." FAO. Accessed February 15, 2014. http: //www.fao.org/docrep/.

[2] Gast, M., and Adrian, J. 1965. "Millets and Sorghum in Ahaggar: Ethnological and Nutritional Study." In Memories of the Center of Anthropological, Prehistorical and Ethnological Researches. Paris: Graphic Arts and Trades, 237-39. (in French)

[3] Ozenda, P. 1991. Flora and Vegetation of the Sahara, 3rd ed., Paris: CNRS. (Flore et végétation du Sahara)

[4] Cornell, H. 2004. "The Functionality of Wheat Starch." In Starch in Food. Structure, Function and Application. Cambridge: Woodhead Publishing, 211-39.

[5] Elmoneim, O. E., Burkhard, S., and Rita, B. 2004. "Selected Physicochemical Properties of Starch Isolated from Fermented Sorghum Flour." Starch/Stärke 56: 582-5.

[6] Food and Agriculture Organization of the United Nations (FAO). 1995. Sorghum and Millets in the Human Nutrition. FAO.

[7] Serna, S., and Rooney, L. 1994. "Structure and Chemistry of Sorghum and Millets." In Sorghum and Millets, Chemistry and Technology. Minnesota: AACC, 69-108.

[8] Bemiller, J., and Whistler, R. 2009. Starch Chemistry and Technology. Amsterdam: Elsevier. 
[9] Kaur, L., Singh, J., McCarthy, O. J., and Singh, H. 2007. "Physico-chemical, Rheological and Structural Properties of Fractioned Potato Starches." J. of Food Eng. 82: 383-94.

[10] Singh, N., Singh, J., Kaur, L., Sodhi, N. S., and Gill, B. S. 2003. "Morphological, Thermal and Rheological Properties of Starches from Different Botanical Sources." Food Chem. 81: 219-31.

[11] Matsuki, J., Yasui, T., Kohyama, K., and Sasaki, T. 2003. "Effects of Environmental Temperature on Structure and Gelatinisation Properties of Wheat Starch." Cereal Chem. 80 (4):476-80.

[12] Rhymer, C., Malcolmon, L., Brown, D., and Duguid, S. 2005. "Effects of Genotype and Environment on the Starch Properties and End-Product Quality of Oats." Cereal Chem. 82: 197-203.

[13] Satin, M. 2002. "Starch as Functional Food." FAO Agricultural and Food Engineering Technologies Service. Accessed January 2014. www.fao.org/ag/magazine/pdf/starches.pdf.

[14] Beta, T., Corke, H., Rooney, L., and Taylor, J. R. N. 2000. "Starch Properties as Affected by Sorghum Grain Chemistry." J. of the Sci. of Food and Agric. 81: 245-51.

[15] Beta, T., and Coke, H. 2001. "Genetic and Environmental Variation in Sorghum Starch Properties." J. of Cereal Sci. 34: $261-8$.

[16] Pérez Sira, E. E., and Amaiz, M. L. 2004. “A Laboratory Scale Method for Isolation of Starch from Pigmented Sorghum." J. of Food Eng. 64: 515-9.

[17] Morrison, W. R., and Laignelet, B. 1983. "An Improved Colorimetric Procedure for Determining Apparent and Total Amylose in Cereal and Other Starches." J. of Cereal Sci. 1: 9-20.

[18] Taylor, J. R. N., Schober, T. J., and Bean, S. R. 2006. "Novel Food and Food Uses for Sorghum and Millets." J. of Cereal Sci. 44: 252-71.

[19] Wang, Y. J., White, P., Pollak, L., and Jane, J. 1993. "Characterization of Starch Structure of 17 Maize Endosperm Mutant Genotypes with Oh43 Inbred Line
Background." Cereal Chem. 70 (2): 171-9.

[20] Radley, J. A. 1976. Examination and Analysis of Starch and Starch Product. Hague, Netherlands: Springer.

[21] Hoseney, R. C. 1986. Principles of Cereal Science and Technology. AACC.

[22] Benmoussa, M., Suhendra, B., Aboubacar, A., and Hamaker, B. R. 2006. "Distinctive Sorghum Starch Granule Morphologies Appear to Improve Raw Starch Digestibility." Starch/Stärke 58: 92-9.

[23] Singh, N., Kaur, L., and Singh Sandhu, K. 2006. "Relationships between Physical, Morphological, Thermal, Rheological Properties of Rice Starches." Food Hydrocol. 20: 532-42.

[24] Takeda, Y., Takeda, C., Suzuki, A., and Hizukuri, S. 1989. "Structures and Properties of Sago Starches with Low and High Viscosities on Amylography." J. of Food Sci. 54 (1): 177-82.

[25] Jane, J., Shen, L., Wang, L., and Maningat, C. C. 1992. "Preparation and Properties of Small-Particles Corn Starch." Cereal Chem. 69 (3): 280-3.

[26] Lindeboom, N., Chang, P. R., and Tyler, R. T. 2004. "Analytical, Biochemical and Physicochemical Aspects of Starch Granule Size, with Emphasis on Small Granule Starches: A Review." Starch/Stärke 56: 89-99.

[27] Jobling, S. 2004. "Improving Starch for Food and Industrial Application." Current Opinion in Plant Biol. 7: 210-8.

[28] Jenkins, P. J., and Donald, A. M. 1998. "Gelatinization of Starch a Combined SAXS/ZAXS/DSC and SANS Study." Carbohydr. Res. 308: 133-47.

[29] Sodhi, N. S., and Singh, N. 2003. "Morphological, Thermal and Rheological Properties of Starches Separated from Rice Cultivars Grown in India." Food Chem. 80 (1): 99-108.

[30] Choi, H., Kim, W., and Shin, M. 2004. "Properties of Korean Amaranth Starch Compared to Waxy Millet and Waxy Sorghum Starches." Starch/Stärke 56: 469-77.

[31] Moorthy, S. N. 2002. "Physicochemical and Functional Properties of Tropical Tuber Starch: A Review." Starch/Stärke 54: 559-92. 